\title{
NiO Nanoparticles: A Highly Efficient Catalyst For One-Pot Three-Component Synthesis of Pyrano[2, 3- d]Pyrimidine Derivatives in Green Media
}

\section{Elahe Sabbaghnasab}

Islamic Azad University Kerman Branch

Enayatollah Sheikhhosseini ( $\sim$ sheikhhosseiny@gmail.com )

Islamic Azad University Kerman Branch https://orcid.org/0000-0003-2973-9768

\section{Original Research}

Keywords: NiO nanoparticles, Pyrano [2, 3-d] pyrimidines, Barbituric acid, Multicomponent reaction

Posted Date: February 15th, 2021

DOl: https://doi.org/10.21203/rs.3.rs-194775/v1

License: (c) (1) This work is licensed under a Creative Commons Attribution 4.0 International License.

Read Full License 


\section{Abstract}

In this paper $\mathrm{NiO}$ nanoparticles are utilized for effective strengthening of annulated pyrano [2, 3- d] pyrimidine synthesis through primary Knoevenagel, the following Micheal and ultimate heterocyclization reactions of aldehyde, malononitrile and barbituric acid. The NiO nanoparticles characteristics are identified through using advanced techniques like IR, UV, EDX, XRD, SEM and TEM. The nano-NiO particles are mostly of below $<100 \mathrm{~nm}$ sizes with uniform sphere shapes. The adopted approach is advantages due to its simple processing, relatively short reaction time, often good to high average yields, convenient workability, and environmental friendliness.

\section{Introduction}

The Nitrogen and Oxygen containing synthetic compounds like heterocyclic rings are very interesting because of possessing a wide spectrum of useful biological and pharmaceutical characteristic and activities [1-12]. Pyrano [2, 3-d] pyrimidines as an example, are structural motifs contained in synthetic and natural compounds that are biologically active. These heterocyclic rings exhibit invaluable biological healing activities, as they perform antitumor [13], hepatoprotective [14], antibronchitic [15] and anti-AIDS behaviours [16]. Accordingly, the efficient synthetization of such compounds and the relevant derivatives entail a motivating challenge for the organic chemistry researchers.

Fortunately, Multicomponent reactions (MCRs) in modern organic synthetic chemistry are regarded highly applicable tools owing to having almost all necessary features to take part in ideal syntheses; features like high atom performance, fast and easy put up with highly time and energy-cost savings, environmentally friendliness as well as providing targeted and diversity-oriented syntheses [17]. Hence, currently devising new multicomponent reactions to produce biomedical and industrial synthetic scaffolds is indispensable.

Numerous regular yet useful producers exist for producing the above compounds. From the abovementioned techniques, the aromatic aldehydes, barbituric acid derivatives and malononitrile with their particular multi-component condensation reactions have been the focal of considerable focus and various bases have proved to be enduring catalysts for such reactions. Its noteworthy however that such protocols have their own drawbacks like corrosion, problematic catalyst recycling and waste generation issues [18-24]. Apparently, a potential of NPs application is using them as catalyst to develop new synthetic methods qualified for transformations in organic settings of environmentally friendly producers. According to some researchers, a number of nano-materials such as the metals metal oxides and NPs with semi-conductor properties could be utilized in organic chemistry as catalysts $[25,26]$.

Hence the development of new synthetic methods, facilitating the provision of organic compounds is most welcomed. Condensation reaction is among those chemical activities for which devising a new environmentally friendly catalyst could potentially provide an approach for dealing with the aforementioned challenges. Upon our previous study on synthesis of organic compounds by 
nanoparticles [26-29], the scope of the present work was to achieve the multi-component pyrano [2, 3-d] pyrimidines by using NiO nano powders as a green, environmentally friendly catalyst (Scheme 1).

\section{Experimental}

\subsection{Materials}

All the chemical materials were supplied from Merck or Sigma Aldrich Co. and were used with no further treatment. We also used distilled water in this paper.

\subsection{Material characterization}

The characterization of supplied materials was performed in terms of physical constants against authentic samples and FT-IR spectroscopy. Thin layer chromatography (TLC) on Merck pre-coated silica gel 60 F254 aluminum sheets as well as UV light visualization technique was used to monitor the products purity and the reactions' progress. A BUCHI 510 melting point device was utilized for determining the material melting points. To record Fourier, transform infrared (FT-IR) spectroscopy a JASCO FT-IR-4000 spectrophotometer was used while the samples were dispersed on $\mathrm{KBr}$ pellets across $4000-400 \mathrm{~cm}^{-1}$ (Bruker, Germany) wavelength range. Also, a Bruker Advance DPX $400 \mathrm{MHz}$ equipment was utilized for recording nuclear magnetic resonance (NMR) spectra, measured on DMSO- $\mathrm{d}_{6}$ relative to tetramethylsilane as an internal standard. Scanning of the X-ray diffraction (XRD) fresh patterns was performed in reflection mode through the use of a powder $X$-ray diffractometer ( $X^{\prime}$ Pert MPD, PAN analytical) equipped with Cu-Ka source of radiation $\left(\lambda=0.154 \mathrm{~nm}\right.$ ) between $10^{\circ}$ and $90^{\circ}$ (2-Theta) having a stage width of 0.010") using a Philips XPERT PRO (Bruker, model D8 Advance). The NiO nanoparticles morphology was examined via scanning electron microscopy (SEM) (Nano SEM 450) (FEl, U.S.). To perform Transmission electron microscope (TEM) measurements, a HITACHI H-7650 electron microscope was used. To measure the UV-VIS spectra a USB-2000 UV-Vis spectrophotometer was used.

\subsection{General process of the NiO nanoparticles synthesis}

Nickel oxide nanoparticles underwent synthetization in free standing powder form using wet chemical synthesis technique. In this study a dissolution of $1 \mathrm{mmol}$ of Nickel (II) nitrate hexahydrate [Ni( $\left(\mathrm{NO}_{3}\right)_{2} \cdot 6 \mathrm{H}_{2} \mathrm{O}$, Merck] was prepared in $10 \mathrm{~mL}$ of polyethylene glycol $\left[\mathrm{H}\left(\mathrm{OCH}_{2} \mathrm{CH}_{2}\right)_{\mathrm{n}} \mathrm{OH}\right)$, Merck]. A magnetic stirrer was then used to stir the solutions for $1 \mathrm{~h}$ at $60^{\circ} \mathrm{C}$. Additionally, separate solutions of 2 $\mathrm{mmol} \mathrm{NaOH}$ and $4 \mathrm{mmol}$ sodium dodecyl sulfate were prepared through dissolution in $10 \mathrm{~mL}$ polyethylene glycol, each stirred for $1 \mathrm{~h}$ using a magnetic stirrer at $60^{\circ} \mathrm{C}$; the prepared solution were then both added to Nickel (II) nitrate solution and stirred using magnetic stirrer for $2 \mathrm{~h}$. at $60^{\circ} \mathrm{C}$. The mixture so prepared underwent 450, 650 and $750 \mathrm{w}$ irradiation for a 4 min time span then left to cool down to reach ambient temperature. Afterwards the centrifugation method was used to form the precipitates; they were then rinsed frequently by ethanol and dried in vacuum oven apparatus at $60^{\circ} \mathrm{C}$ to finally accumulate the nickel oxide nanoparticles. 


\subsection{General preparation process of benzopyrano [2,3-d] pyrimidinones}

Aromatic aldehydes 1 (1.9 mmol), malononitrile 2 (2.2), barbituric acid or 2-thiobarbiturate $3(2 \mathrm{mmol})$ and $\mathrm{NiO}$ nanoparticles $\left(0.04 \mathrm{~g}\right.$ ) were taken in an RB flask with $10 \mathrm{~mL} \mathrm{H}_{2} \mathrm{O}$ as solvent and stirred for appropriate time at reflux condition. Thin layer chromatography was used to monitor the reactions, after the completion of which $5 \mathrm{~mL}$ of DMSO was introduced into the reaction mixture. Afterwards the solid compound (catalyst) was separated through filtration, and water was added to the remaining solution so as to form precipitates. The precipitates were filtered and washed by ethanol to acquire the derivatives of pure product benzopyrano [2, 3-d] pyrimidine derivatives. Spectral data of the selected compound is given below:

7-Amino-2,3,4,5-tetrahydro-5-(3-nitrophenyl)-2,4-dioxo-1H-pyrano [2, 3-d] pyrimidine-6-carbonitrile (4a): M.

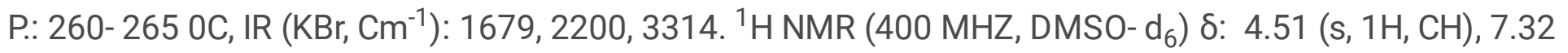
(2H, brs- NH2), $7.61(1 \mathrm{H}, \mathrm{t}, \mathrm{J}=8.0 \mathrm{H}, \mathrm{H}-\mathrm{Ar}), 8.10-8.11(\mathrm{~m}, 2 \mathrm{H}, \mathrm{H}-\mathrm{Ar}), 11.72(\mathrm{~s}, 1 \mathrm{H}, \mathrm{NH}), 12.47(\mathrm{~s}, 1 \mathrm{H}, \mathrm{NH}) .{ }^{13} \mathrm{C}$ $\operatorname{NMR}\left(100 \mathrm{MHz}, \mathrm{DMSO}-\mathrm{d}_{6}\right)$ ס: 35.4, 58.3, 88.3, 119.6, 122.8, 122.9, 130.6, 135.3, 147.2, 148.5, 150.4, 153.2, 158.9, $163.2 \mathrm{ppm}$.

\section{Results And Discussion}

\subsection{Characterization of nickel oxide nanoparticles}

To investigate the impacts of microwave on the nickel oxide nanoparticles' synthesis, the nickel oxide nanoparticles were prepared by applying microwave various power levels (450, 650 and $750 \mathrm{~W})$. Figs. (1a, $1 \mathrm{~b}$ and $1 \mathrm{c}$ ) respectively illustrate the NiO nanoparticles scanning electron microscope images. The SEM image represented a spherical structure of the $\mathrm{NiO}$ nanoparticles, revealing that they were distributed widely under the effect of agglomeration, probably due to the presence of sodium dodecyl sulfate. The below fig. (1a) SEM image of NiO nanoparticles demonstrates an area of narrow distribution of 50-60 nm particle size, suggesting that $450 \mathrm{w}$ is providing the suitable radiation power condition.

As can be seen from the obtained TEM images, the NiO nanoparticles are spherical in shape. The TEM image Fig. (2) shows that $\mathrm{NiO}$ mostly spherical nanoparticle sizes lie somewhere between $40-50 \mathrm{~nm}$, while heavy agglomeration can be spotted in some areas. In this study the TEM and SEM imaging systems measurements confirmed the average particle size obtained from Debye-Scherer formula through XRD patterns.

Infrared spectrometer (IR) measuring $\mathrm{NiO}$ nanoparticles exhibited some absorption bonds at $1409 \mathrm{~cm}^{-}$ ${ }^{1}$ and $11590 \mathrm{~cm}^{-1}$ relative to $\mathrm{NiO}$ spinal structure. Also $600-1200 \mathrm{~cm}^{-1}(\mathrm{Ni}-\mathrm{O}), 2850$ and $2918\left(\mathrm{CH}_{2}-\mathrm{SDS}\right)$ and 1082, 1362 (S=O-SDS) adsorption bonds were consistent with the SDS-based synthesized NiO nanoparticles.

The following main elements were obtained from the energy dispersive X-ray (EDX) spectroscopy results: $\mathrm{Ni}(34 \%), \mathrm{O}(28 \%), \mathrm{C}(24 \%)$ and $\mathrm{Na}(18 \%)$. The NiO nanonoparticles' XRD spectrum, synthesized under 
microwave optimal irradiations condition has been illustrated in Fig. (3). According to the Xpert high score software data, the synthesized sample XRD pattern with its JCPD card No. 47-1049 acknowledges the fruitful synthesis of $\mathrm{NiO}$ nanoparticles at $0.058 \mathrm{~S}^{-1}$ scanning rate across $10^{\circ}$ to $80^{\circ}$ in spinal phase spectrum. The below XRD pattern also contains - in addition to the NO diffusers-the $\mathrm{Ni}(\mathrm{OH})_{2}$ and SDS diffractions. A significant absorption peak of about $260 \mathrm{~nm}$ can be seen in the UV-VIS spectra of NiO nanoparticles.

\subsection{Synthesis of pyrano [2, 3-d] pyrimidine derivatives by using NiO nanoparticles}

To extend the present study to experimental research, so that high performance MCRs are developed for the provision of annulated bioactive molecules of pyrimidine $[29,31]$, here we claim that in aqueous media, through one-pot three-component domino Knoevenagel- Michael addition reactions, the NiO nanoparticles led to catalysis of fast, efficient, and simple synthesis of pyrano[2,3-d]pyrimidine derivatives (Scheme 1).

Initially, as a model reaction, the three-component reaction of 3-nitrobenzaldehyde 1a, barbituric acid 2a, and malononitrile 3 was employed to examine different solvents including: $\mathrm{MeOH}, \mathrm{EtOH}, \mathrm{H}_{2} \mathrm{O}, \mathrm{CHCl}_{3}$ and $\mathrm{CH}_{2} \mathrm{Cl}_{2}$ (Table 1) in the presence of $\mathrm{NiO}$ nanoparticles $(0.04 \mathrm{~g}$ ). The appropriate chosen solvent for utilization in the reaction was $\mathrm{H}_{2} \mathrm{O}$. Consequently, as Table 1 shows, the three-component model reaction was conducted while various amounts of catalysts were available. In order to come upon the optimal amount of catalyst for accessing pyrano [2, 3-d] pyrimidine 4a, the above investigation was conducted. According to the results, $\mathrm{H}_{2} \mathrm{O}$ with $0.04 \mathrm{~g}$ of $\mathrm{NiO}$ nanoparticles as the catalyst was the optimal reaction media for the formation of the products $4 a$.

Once the reaction conditions were optimized, the suitability and effectiveness of the same procedure were surveyed by conducting the reaction through various readily accessible and simple substrates under the optimum conditions. Thus, under the optimum conditions, different aromatic aldehydes containing electron-donating and electron-withdrawing groups, namely, $\mathrm{NO}_{2}, \mathrm{~N}, \mathrm{~N}$-dimethyl and $\mathrm{OCH}_{3}$ in the para and ortho positions of the benzene ring were came into reaction with malononitrile and barbituric or thiobarbituric acid. As entries 1-12 in Table 4 show, within short reaction times, the concerned products were achieved in moderate-good isolated yields. Also, as entries 8-12 in Table 2 suggest, under the optimum conditions, thiobarbiturate acid was employed, giving high yields of the desired products.

The proposed mechanism of the one-pot reaction between benzaldehyde derivatives, malononitrile and barbituric acid was described in Scheme 2 . The acidic surface probably coordinates with the nitrogen and oxygen of the carbonyl carbon on which a partial positive charge appears. Based on this proposed mechanism, NiO nanoparticles are capable of activating aldehyde carbonyl group whilst accelerating barbituric acid enolization. The higher reactivity of the iminium group is utilized to facilitate Knoevenagel condensation between benzaldehyde 1 and malononitrile 2, which produce intermediate 6 that is attacked by the enolized barbituric acid 5 for generation of product 4 after proton transfer and tautomerization of intermediate 7 (Scheme 2). 
In summary, by employing the multi-component reaction of malononitrile, barbituric acid, and aromatic aldehydes, in the presence of nanoparticles of $\mathrm{NiO}$ as a catalyst, an efficient and rapid synthesis route was developed for pyrano [2,3-d] pyrimidine derivatives in this study resulting in good yields. One can cite several advantages for the same synthesis: it is simple to prepare $\mathrm{NiO}$ nanoparticle as the catalyst, the easy accessibility to the starting materials, high reaction times, the clean reaction profile, the easy workup and green media.

\section{References}

1. M. Ghashang, M. Kargar, M. R. Shafiee, S.S. Mansoor, A. Fazlinia, H. Esfandiari, CuO Nano-structures Prepared in Rosmarinus Officinalis Leaves Extract Medium: Efficient Catalysts for the Aqueous Media Preparation of Dihydropyrano [3, 2-c] chromene Derivatives. Recent Pat. Nanotech 9(3), 204211 (2015).

2. M. Ghashang, S.S. Mansoor, M.R. Mohammad Shafiee, M. Kargar, M. Najafi Biregan, F. Azimi, H. Taghrir, Green chemistry preparation of MgO nanopowders: efficient catalyst for the synthesis of thiochromeno [4, 3-b] pyran and thiopyrano [4, 3-b] pyran derivatives." J. Sulfur Chem. 37(4), 377-390 (2016).

3. M. Ghashang, S.S. Mansoor, K. Aswin, Thiourea dioxide: An efficient and reusable organocatalyst for the rapid one-pot synthesis of pyrano [4, 3-b] pyran derivatives in water. Chin. J. Catal. 35(1), 127133.4 (2014).

4. A. Baziar, M. Ghashang, Preparation of pyrano [3, 2-c] chromene-3-carbonitriles using ZnO nanoparticles: a comparison between the Box-Behnken experimental design and traditional optimization methods. React. Kinet. Mechan. Catal. 118(2), 463-479 (2016).

5. M. Ghashang, $\mathrm{ZnAl}_{2} \mathrm{O}_{4}-\mathrm{Bi}_{2} \mathrm{O}_{3}$ composite nano-powder as an efficient catalyst for the multicomponent, one-pot, aqueous media preparation of novel $4 \mathrm{H}$-chromene-3-carbonitriles. Res. Chem. Intermed. 42(5), 4191-4205 (2016).

6. M. Dehbashi, M. Aliahmad, M.R. Mohammad Shafiee, M. Ghashang, Nickel-doped $\mathrm{SnO}_{2}$ Nanoparticles: Preparation and Evaluation of Their Catalytic Activity in the Synthesis of 1-amido Alkyl-2-naphtholes. Synth. React. Inorg. Metal-Org. Nano-Metal Chem. 43(9), 1301-1306 (2013).

7. M. Ghashang, Zinc hydrogen sulfate promoted multi-component preparation of highly functionalized piperidines. Lett. Org. Chem. 9(7), 497-502 (2012).

8. M. Ghashang, Preparation and application of barium sulfate nano-particles in the synthesis of 2, 4, 5triaryl and N-aryl (alkyl)-2, 4, 5-triaryl imidazoles. Curr. Org. Synth. 9(5), 727-732 (2012).

9. M.M.R. Shafiee, M. Ghashang, A. Fazlinia, Preparation of 1, 4-dihydropyridine derivatives using perchloric acid adsorbed on magnetic $\mathrm{Fe}_{3} \mathrm{O}_{4}$ nanoparticles coated with silica. Curr. Nanosci. 9(2), 197-201 (2013).

10. H. Taghrir, M. Ghashang, M.N. Biregan, Preparation of 1-amidoalkyl-2-naphthol derivatives using barium phosphate nano-powders. Chin. Chem. Lett. 27(1), 119-126 (2016). 
11. M.R.M. Shafiee, S.S. Mansoor, M. Ghashang, A. Fazlinia, Preparation of 3, 4, 5-substituted furan-2 $(5 \mathrm{H})$-ones using aluminum hydrogen sulfate as an efficient catalyst. C. R. Chim. 17(2), 131-134 (2014)

12. M. Zare, M. Ghashang, A. Saffar-Teluri, BaO-ZnO nano-composite efficient catalyst for the photocatalytic degradation of 4-chlorophenol. Biointerface Res. Appl. Chem. 6(1), 1049-1052 (2016).

13. J. A. Valderrama, P. Colonelli, D. Vasquez, M.F. Gonzalez, J.A. Rodriguez, C. Theoduloz, Studies on quinones. Part 44: novel angucyclinone Nheterocyclic analogues endowed with antitumoral activity. Bioorg. Med. Chem. Lett. 16(24), 10172-10181 (2008).

14. S. Furuay, T. Ohtaki, Pyranopyrimidine derivatives, their production and use. Eur. Pat. Appl. EP608565, 1994.

15. M.C. Bagley, D.D. Hughes, M.C. Lubinu, E.A. Merrit, P.H. Taylor, N.C.O. Tomkinson, Microwave-assisted synthesis of pyrimidine libraries. QSAR Comb. Sci. 23(1-10), 859-867 (2004).

16. M. Nogueras, J. Cobo, M.L. Quijano, M. Melguizo, A. Shchez, M.Melgarejob, Selective Synthesis of 6Ribo- (and Xylo) Pyrano and Furano Aminopyridines. Anticancer and Anti-AIDS Activities. Nucleosides Nucleotides Nucleic Acids 13(1-3), 447-457 (1994).

17. P.A. Wender, Toward the ideal synthesis and molecular function through synthesis-informed design. Nat. Prod. Rep. 31(4), 433-440 (2014).

18. F. Seeliger, S.T.A. Berger, G.Y. Remennikov, K. Polborn, H. Mayr, Electrophilicity of 5-benzylidene-1,3dimethylbarbituric and -thiobarbituric acids. J. Org. Chem. 72(24), 9170-9780 (2007).

19. J.M. Khurana, K. Vij, Nickel nanoparticles as semiheterogeneous catalyst for one-pot, threecomponent synthesis of 2-amino-4H-pyrans and pyran annulated heterocyclic moieties. Synth. Commun. 43(17), 2294-2304 (2013).

20. D. Azarifar, R. Nejat-Yami, F. Sameri, Z. Akrami, Ultrasonicpromoted onepot synthesis of $4 \mathrm{H}-$ chromenes, pyrano[2,3-d]pyrimidines, and 4Hpyrano[2,3-c]pyrazoles. Lett. Org. Chem. 9(6), 435-439 (2012).

21. M.N. Elinson, A.I. Ilovaisky, V.M. Merkulova, T.A. Zaimovskaya, G.I. Nikishin, Electrocatalytic multicomponent assembling of aldehydes, $\mathrm{N}$-alkyl barbiturates and malononitrile: an efficient approach to pyrano [2, 3-d] pyrimidines. Mendeleev Commun. 3(21), 122-124 (2011).

22. I. Devi, B.S.D. Kumar, P.J.A. Bhuyan, novel three-component one-pot synthesis of pyrano[2,3d]pyrimidines and pyrido[2,3-d]pyrimidines using microwave heating in the solid state. Tetrahedron Lett. 44(45), 8307-8310 (2003).

23. M.N. Elinson, F.V. Ryzhkov, V.M. Merkulova, A.I. Ilovaisky, G.I. Nikishin, Solvent-free multi-component assembling of aldehydes, $\mathrm{N}, \mathrm{N}$-dialkyl barbiturates and malononitrile: fast and efficient approach to pyrano[2,3-d]pyrimidines. Heterocycl. Commun. 20(5), 281-284 (2014).

24. A. Khazaei, A. Ranjbaran, F. Abbasi, M. Khazaei, A.R. Moosavi-Zare, Synthesis, characterization and application of $\mathrm{ZnFe}_{2} \mathrm{O}_{4}$ nanoparticles as a heterogeneous ditopic catalyst for the synthesis of pyrano[2,3-d] pyrimidines. RSC Adv. 5(18), 13643-13647 (2015). 
25. N. Erfaninia, R. Tayebee, E.L. Foletto, M.M. Amini, M. Dusek, F.M. Zonoz, Preparation of magnetically recyclable $\mathrm{ZnFe}_{2} \mathrm{O}_{4}$ nanoparticles by easy single-step co-precipitation method and their catalytic performance in the synthesis of 2-aminothiophenes. Appl. Organomet. Chem. 32(2), e4047 (2018).

26. N. Budhiraja, A. Sharma, S. Dahiya, R. Parmar, V. Vidyadharan, Synthesis and optical characteristics of silver nanoparticles on different substrates. Int. lett. chem. phys. astron. 14, 80-88 (2013).

27. M. Yahyazadehfar, S.A. Ahmadi, E. Sheikhhosseini, D. Ghazanfari, High-yielding strategy for microwave-assisted synthesis of $\mathrm{Cr}_{2} \mathrm{O}_{3}$ nanocatalyst. J. Mater. Sci.: Mater. Electron., 31, 11618-11623 (2020).

28. H. Maaref, E. Sheikhhosseini, M.M. Foroughi, M.R. Akhgar, S. Jahani, Characterization of bis-Schiff bases synthesized using $\mathrm{ZnFe}_{2} \mathrm{O}_{4}$ nanoparticles as catalyst, and examination of their antibacterial and in vitro cytotoxic properties. Appl. Organomet. Chem., 34(4), e5557 (2020).

29. M. Moghaddam-Manesh, D. Ghazanfari, E. Sheikhhosseini, M. Akhgar, Synthesis of bioactive magnetic nanoparticles spiro [indoline-3, 4'-[1, 3] dithiine]@ $\mathrm{Ni}\left(\mathrm{NO}_{3}\right)_{2}$ supported on $\mathrm{Fe}_{3} \mathrm{O}_{4} @ \mathrm{SiO}_{2} @ \mathrm{CPS}$ as reusable nanocatalyst for the synthesis of functionalized 3, 4-dihydro-2Hpyran. Appl. Organomet. Chem., 34(4), e5543 (2020).

30. M. Yahyazadehfar, E. Sheikhhosseini, S.A. Ahmadi, D. Ghazanfari, Microwave-associate synthesis of $\mathrm{Co}_{3} \mathrm{O}_{4}$ nanoparticles as an effcient nanocatalyst for the synthesis of arylidene barbituric and Meldrum's acid derivatives in green media. Appl. Organomet. Chem., 33(9), e5100.G (2019).

31. E. Sheikhhosseini, D. Ghazanfari, V. Nezamabadi, 2013. A new method for synthesis of tetrahydrobenzo [b] pyrans and dihydropyrano [c] chromenes using p-dodecylbenzenesulfonic acid as catalyst in water. Iran. J. Catal., 3(4), 197-201 (2013).

\section{Tables}

Table. 1 Optimization of reaction condition for the yield of 7-amino-2,3,4,5-tetrahydro-5-(3nitrophenyl)-2,4-dioxo-1H-pyrano[2,3-d]pyrimidine-6-carbonitrile (4a) 


\begin{tabular}{|lllccc|}
\hline Entry & Nanocatalyst & Solvent & Temperature & Time (min) & Yield (\%) $^{\mathrm{a}}$ \\
\hline 1 & catalyst free & $\mathrm{H}_{2} \mathrm{O}$ & r.t. & $24 \mathrm{~h}$ & No reaction \\
2 & catalyst free & $\mathrm{H} 2 \mathrm{O}$ & $100^{\circ} \mathrm{C}$ & $24 \mathrm{~h}$ & trace \\
3 & $\mathrm{NiO}(0.03 \mathrm{~g})$ & $\mathrm{H}_{2} \mathrm{O}$ & $100{ }^{\circ} \mathrm{C}$ & $5 \mathrm{~min}$ & 75 \\
4 & $\mathrm{NiO}(0.04 \mathrm{~g})$ & $\mathrm{H}_{2} \mathrm{O}$ & $100{ }^{\circ} \mathrm{C}$ & $4 \mathrm{~min}$ & 78 \\
5 & $\mathrm{NiO}(0.05 \mathrm{~g})$ & $\mathrm{H} 2 \mathrm{O}$ & $100{ }^{\circ} \mathrm{C}$ & $120 \mathrm{~min}$ & 55 \\
6 & $\mathrm{NiO}(0.06 \mathrm{~g})$ & $\mathrm{H}_{2} \mathrm{O}$ & $100{ }^{\circ} \mathrm{C}$ & $130 \mathrm{~min}$ & 50 \\
8 & $\mathrm{NiO}(0.04 \mathrm{~g})$ & $\mathrm{MeOH}$ & $70^{\circ} \mathrm{C}$ & $40 \mathrm{~min}$ & 50 \\
9 & $\mathrm{NiO}(0.04 \mathrm{~g})$ & $\mathrm{EtOH}^{\circ}$ & $80^{\circ} \mathrm{C}$ & $24 \mathrm{~h}$ & 25 \\
10 & $\mathrm{NiO}(0.04 \mathrm{~g})$ & $\mathrm{CHCl}_{3}$ & $60^{\circ} \mathrm{C}$ & $24 \mathrm{~h}$ & trace \\
11 & $\mathrm{NiO}(0.04 \mathrm{~g})$ & $\mathrm{CH}_{2} \mathrm{Cl}_{2}$ & $40^{\circ} \mathrm{C}$ & $24 \mathrm{~h}$ & trace \\
\hline
\end{tabular}

Table. 2 Pyrano[2,3-d]pyrimidine derivatives obtained by the reaction of aromatic aldehydes, malononitrile with barbituric and thiobarbituric acid using $\mathrm{NiO}$ nanoparticles as catalyst

\begin{tabular}{|c|c|c|c|c|c|c|}
\hline Entry & $\mathrm{Ar}$ & $\mathrm{X}$ & Product & Time (min) & Yield (\%)a & $\mathrm{Mp}\left({ }^{\circ} \mathrm{C}\right)$ \\
\hline 1 & $3-\mathrm{NO}_{2} \mathrm{C}_{6} \mathrm{H}_{4}$ & $\mathrm{O}$ & $4 a$ & 4 & 78 & $260-265$ \\
\hline 2 & $\mathrm{C}_{6} \mathrm{H}_{4}$ & $\mathrm{O}$ & $4 \mathrm{~b}$ & 45 & 71 & $200-210$ \\
\hline 3 & $4-\left(\mathrm{Me}_{2} \mathrm{~N}\right) \mathrm{C}_{6} \mathrm{H}_{4}$ & $\mathrm{O}$ & $4 \mathrm{c}$ & 5 & 77 & $252-258$ \\
\hline 4 & $4-\mathrm{MeOC}_{6} \mathrm{H}_{4}$ & $\mathrm{O}$ & $4 \mathrm{~d}$ & 15 & 64 & $310-315$ \\
\hline 5 & $2,4-(\mathrm{MeO})_{2} \mathrm{C}_{6} \mathrm{H}_{4}$ & $\mathrm{O}$ & $4 e$ & 10 & 76 & $262-268$ \\
\hline 6 & $3,4,5-(\mathrm{MeO})_{3} \mathrm{C}_{6} \mathrm{H}_{3}-$ & $\mathrm{O}$ & $4 \mathrm{f}$ & 5 & 75 & $222-227$ \\
\hline 7 & $3-\mathrm{OHC}_{6} \mathrm{H}_{4}$ & $\mathrm{O}$ & $4 \mathrm{~g}$ & 10 & 37 & $172-179$ \\
\hline 8 & $4-\left(\mathrm{Me}_{2} \mathrm{~N}\right) \mathrm{C}_{6} \mathrm{H}_{4}-$ & S & $4 h$ & 5 & 74 & $265-270$ \\
\hline 9 & $3-\mathrm{NO}_{2} \mathrm{C}_{6} \mathrm{H}_{4}$ & $\mathrm{~S}$ & $4 \mathrm{i}$ & 10 & 41 & $192-196$ \\
\hline 10 & $2,4-(\mathrm{MeO})_{2} \mathrm{C}_{6} \mathrm{H}_{4}$ & $\mathrm{~S}$ & $4 j$ & 20 & 74 & $312-318$ \\
\hline 11 & $3,4,5-(\mathrm{MeO})_{3} \mathrm{C}_{6} \mathrm{H}_{3}-$ & S & $4 \mathrm{k}$ & 5 & 95 & $290-295$ \\
\hline 12 & $\mathrm{C}_{6} \mathrm{H}_{4}$ & $\mathrm{~S}$ & 41 & 20 & 17 & $234-238$ \\
\hline
\end{tabular}



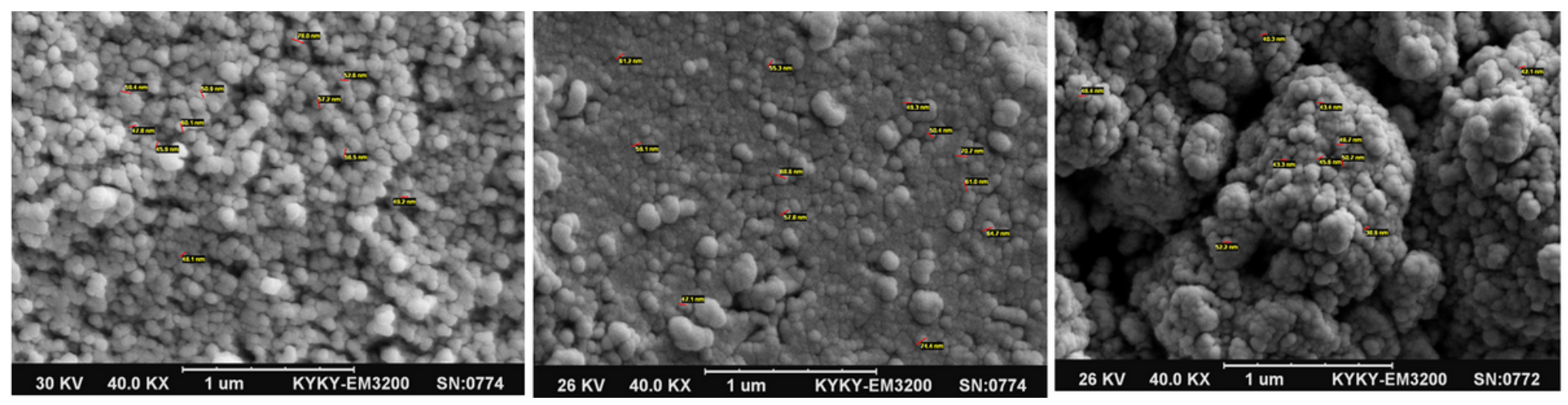

\section{Figure 1}

a SEM image of the NiO nanoparticles (450 W), b SEM image of the NiO nanoparticles (650 W), c SEM image of the NiO nanoparticles (750 W).

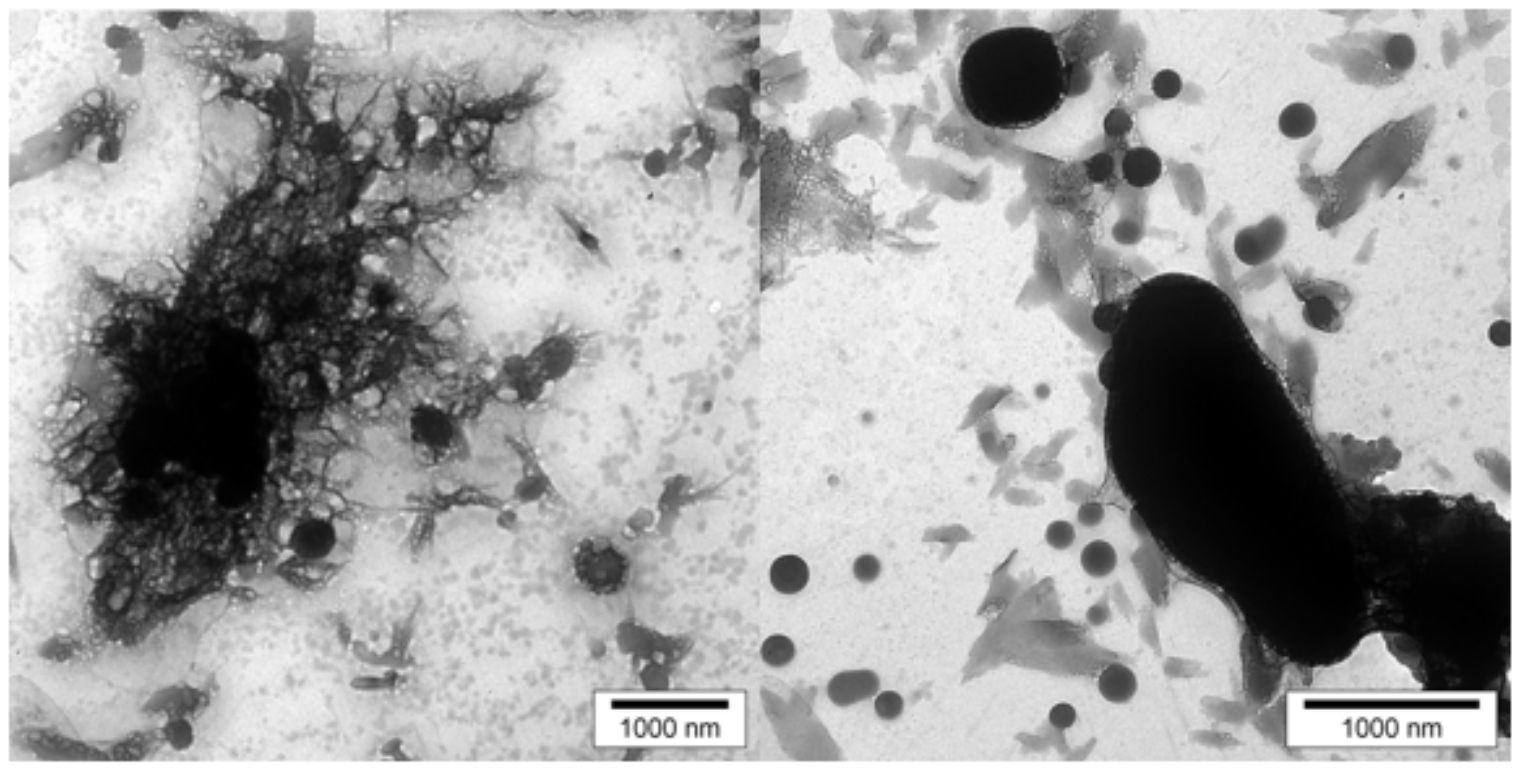

Figure 2

TEM image of NiO nanoparticles. 


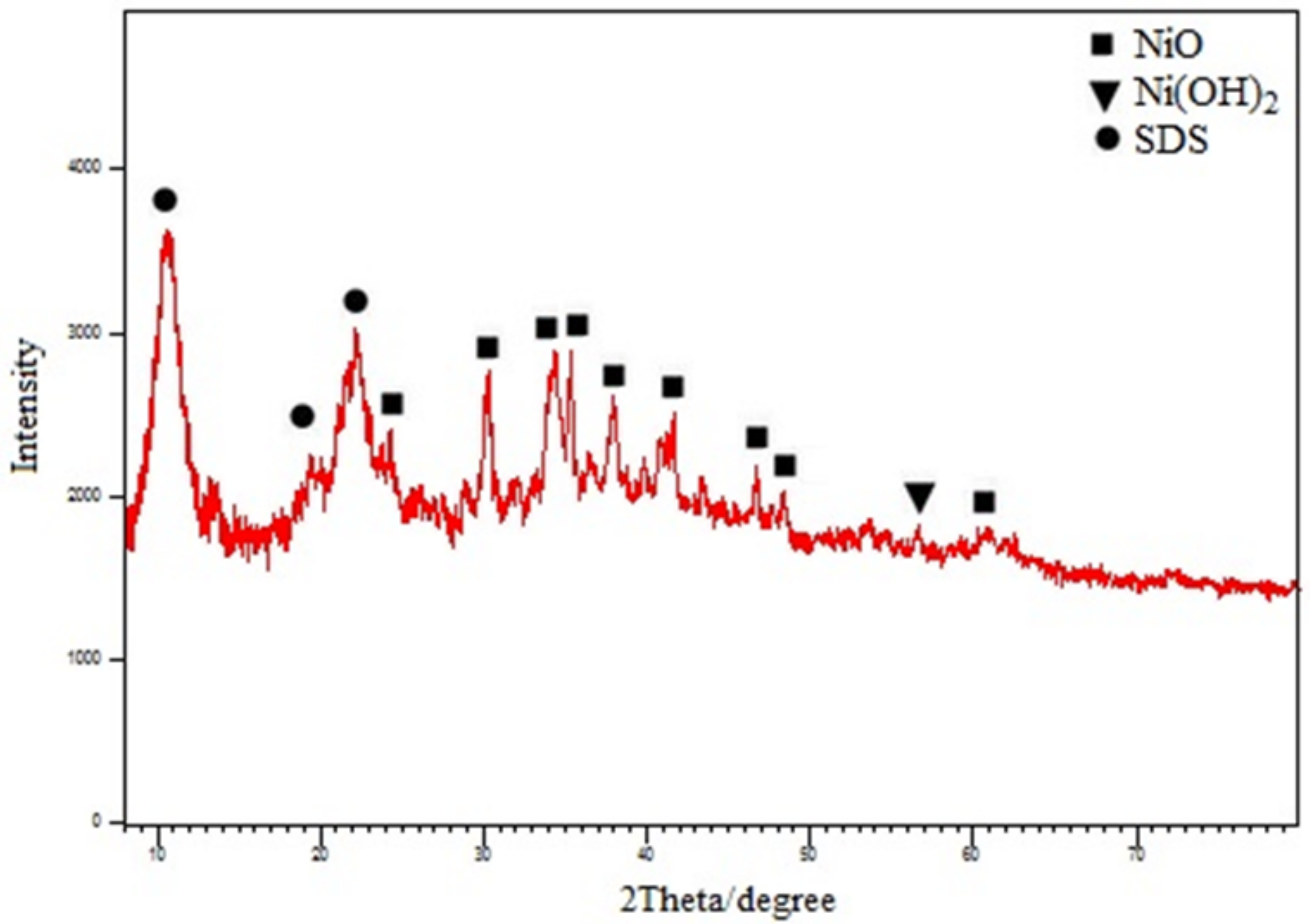

Figure 3

XRD pattern of the NiO nanoparticle.

\section{Supplementary Files}

This is a list of supplementary files associated with this preprint. Click to download.

- Scheme01.png

- Scheme02.png 